$9(1)(2020) 40-47$
Indonesian Journal of Early Childhood
Education Studies

\title{
The Role of Parents at Mathematics Learning Innovation in Early Education
}

\author{
Miftah Sigit Rahmawati ${ }^{\bowtie}$, Irman Amri \\ DOI: http://dx.doi.org/10.15294/ijeces.v9i1.38349
}

Universitas Muhammadiyah Sorong, Indonesia

\section{History Article \\ Submitted 17 April 2020 Revised 13 May 2020 Accepted 4 June 2020}

\section{Keywords}

Early Education; Montessor; Pedagogical Mathematics Learning

\begin{abstract}
In digital era, it is possible for the term "home education" which presents the role of the family to the childhood education. The development of children's mathematics involved role of parents lies, so a mechanism needs to be established about the importance of mathematics learning in the early years and its forms about mathematical activities for children. Learning mathematics in early childhood connects the use of formative values, namely observation, assignments, and interviews for planned teaching. Pedagogical practice focuses on the involvement of children in games, reading stories/picture books, doing project work, and learning mathematics through art or physics. This gives the explanation that children in early education with their settings involve mathematical ideas. This research aims to provide solutions and ideas for parents in teaching children of early age (0-3) years old on mathematics. This research also provides an explanation of parental involvement in teaching mathematics by playing together and preparing children to face mathematics at the next level. The research method used is based on field research, literature studies, and observations. Report of evaluation and observation provide good results with the use of one of the learning methods, namely the montessori method. It also gives an explanation of the importance of togetherness of children and parents in learning mathematics without eliminating children's play time.
\end{abstract}

\section{How to Cite}

Rahmawati, M. S., \& Amri, I. (2020). The Role of Parents at Mathematics Learning Innovation in Early Education. Indonesian Journal of Early Childhood Education Studies, 9(1), 40-47. 


\section{INTRODUCTION}

Mathematics is recognized as an important initial skill and parents are recognized as a vital source of mathematical development. If parents have a positive influence for their children in every life and every education, then it will make sucess in the future. The ways of parentchild interaction which can support the development of early mathematical skills in young children still must be fully examined. It have to do some detailed research studies such as mathematics learning experiences. These use to get better learning method for understanding mathematical knowledge gained at home. Educators need to understand how mathematics learning is promoted by young children's engagement in play, and how best they can support that learning. Thus, parents can help children to maximise their learning by helping them to represent and to reflect on their experiences. Learning through play is seen as fundamental to good mathematics pedagogy in early childhood (Dooley, et al., 2014). Excellence in mathematics education requires equally high expectations and strong support for all students. This implies to mathematics early education. More greater attention must be given to early mathematics experiences, such increased awareness and effort recently have occurred with respect to early foundations of literacy. Similarly, increased energy, time, and wide-scale commitment to the early years will generate significant progress in mathematics learning (NCTM, 2002). The purpose of this research is explore how parents support their children education from an early age (0-3 years) related to mathematics with joint activities. This research is interesting to discuss because it can show how parents can involve children in mathematical thinking at home and introduce mathematics by doing fun activities together. Specifically, this paper review home activities that encourage mathematical interaction. Parents provide guidance during home activities that support children's development, and parent's influence on the importance of early mathematics learning. It can be said that activities on this study is related to mathematical pedagogy, hopefully it can explore the potential benefits of learning activities that can be used as a basic for further mathematics lessons in the future. Furthermore, this paper has the aim of examining the impact of parents in early childhood related in learning mathematics. It also recomend the steps for stimulus children and parents involvement in early childhood education on learning mathematics.

Mother is the first and best educator.
Whatever the social status and occupation of a woman, being a mother is more influential and has more power than a husband who becomes a father (Ardita \& Rabije, 2016). Consequently, it is also vital that the mother's emotional state, her behavior, attitudes, beliefs, working environment as well as her profession particularly during the period of pregnancy need to be watched and controlled (Cyrus, et al., 2010). Although fathers also have a big influence in educating children but not as much as the influence of mothers. The key role of parents in supporting children for involved in mathematics needs to be emphasized. Children will understand and find the meaning from all abstractions based on concrete situations and experiences on their surroundings. Teachers are said to be succeed learning in preschool, when children are given learning by built it based on children's daily activities, integrating cultural background, language, and mathematical ideas and strategies. In addition, teachers create meaning related to context, and offer opportunities for children to actively participate, help children learn mathematics and mathematical ideas and develop positive beliefs about mathematics and themselves. Children in age 0-3 years need teacher who always near the child every day, introduce the world and surroundings. In fact, the teacher is their mother.

The home component of the intervention was developed to enable parents to support their children's mathematical development. The inclusion of home mathematics activities was based on the assumption that the home environments are important in fostering children's early mathematical knowledge and more generally, a successful preparation for preschool. Parents should receive training, resources, and support on culturally appropriate ways to create home learning environments that foster high expectations for children's success in mathematics (Rose, et al., 2013). Strategies designed to support parents become better educator by observation and discussion about children and involvement in mathematical activities is needed. This paper aim to predict mathematics learning for their children and to give some mechanisms for built the importance of mathematics learning in the early years especially 0-3 years old. Furthermore, it give some idea of mathematics activities and learning for young children ( $0-3$ years old). This is the background of the important role of parents in the mathematical development of their children.

Mathematics is one of the knowledge that humans need in everyday life. For example, after waking up you see that there is numbers in a 
clock, a number known in money to spend everything, counting an object that is owned such as counting cookies in plate, classifying objects based on certain conditions. This proves that mathematics is very close to everyday life. Mathematics can be learned in various ways. Perry and Dockett (2007) believe that all children in their early childhood years are capable of accessing powerful mathematical ideas that are both relevant to their current lives and form a critical foundation for their future mathematical and other learning. Children should be given the opportunity to access these ideas through high quality child-centred activities in their homes. In preschool children explore mathematics with comparing numbers, finding patterns, learning geometry by arrange blocks, balancing the height of a building beam. (Dina, 2017) In early childhood mathematics learning, mathematics is an abstract system which is experience of organizing and sorting. Itdefine the early childhood mathematics as follows: 1. One-to-one correspondence, includes the distribution of objects. It is related to direct relationships with each other such as one cake for each child; 2 . Sorting, includes the ability to place things in their sort. For example: sorting by size (smallest to large) or by number; 3 . Counting, includes the ability to demonstrate an understanding of numbers and the sum; 4 . Calculation is the process of adding and subtracting, in line with being experienced concretely; 5 . Classification, includes the ability for grouping objects according to their attributes (for example: color, shape, size); 6. Measurement is the process of finding a number from a standard unit of an object; 7. Comparison, includes the ability to determine an object. It is bigger, smaller, or the same as another through measurement; 8. Geometry is the study of dimention relations; 9 . Pattern is a theme that connects mathematical topics. This encourages children to look at relationships, find relationships and make general conclusions and conjectures.

To strengthen the foundation of learning mathematics in early childhood, it is necessary to build a positive attitude towards mathematics. To build a positive attitude towards learning mathematics, need to be prepared some support activities which is suitable to the age of children's cognitive development (Khadijah, 2016). It start from the curriculum, methods and tools. A curriculum is more than a collection of activities. It must be coherent, focused on important mathematics, and well articulated across the grades. This paper was focused on some equalized curriculum as preschool, it called "building blocks curriculum" and "pre-K mathematics curriculum". Building blocks is a National Science Foundation-funded pre-K to grade 2 mathematics curriculum development project designed to comprehensively address recent standar for early mathematics eduation for all children (Sarama \& Clement, 2002). For Clement and Sarama, a pre-Kindergarten to grade 2 is intended to help children find and axtend mathematics in everyday activities. These learning are empirically derived and provide useful frameworks for the development of mathematical tinking about particular topics over time such as shape or measurement. It beginning with recognizing length is an attribute of object. These determined that building blocks curriculum basic approach would be finding the mathematics learning and developing mathematics from children's activities. The material are designed to help children extend and mathematize their everyday activities. These activities are designed based on children experiences and interests, with an emphasis on supporting the development (Sarama \& Clement, 2007). For this research, it use a manipulatives media such as everyday object. Similar, Starley and Klein developed "the pre-K mathematics curricula". (IES, 2013) Pre-K Mathematics is a supplemental curriculum designed to develop the informal mathematical knowledge and skills of preschool children with content organized into seven units. Specific mathematics concepts and skills from each unit are taught in activities with concrete manipulatives. The curriculum also includes take-home activities that parallel the smallgroup classroom activities, and are designed to help parents support their children's mathematical development at home. (Starkey \& Klein, 2000). They conducted an intervention study in which high quality mathematics experiences were provided to low-income pre-kindergarten children through a home mathematics curriculum. Studies have shown that pre-K curricula is effective at improving preschool students mathematics knowledge. It was found that significantly more extensive mathematical knowledge developed in intervention children than in control children. Thus, a mathematics-focused intervention directed at the home learning environment can be effective in supporting low-income children's mathematical development. However, a limitation of an intervention in the home environment is that it can only be effective for children whose parents are willing and able to provide sustained mathematical support.

For the past several years, we have been investigating young children's (aged 4-7 years) engagement with various mathematical activities 
within three major domains: number concepts, geometry and repeating patterns. According to Ainsworth (Prentice, et al., 2004), there are three functions of multiple external representations: to complement, to constrain and to construct. The aim of this study is to explore these three functions within different mathematical contexts. its review studies of young children engaging with concrete, figural and tablet representations of three mathematical concepts: counting objects, identifying triangles and completing repeating patterns. This paper prepare everything like that for children to learn mathematics at that time, because this research is try to apply for children since baby until pre-school. It is good if learning mathematics reflects all the characteristics of early childhood education which can be applied in real life, even though the child has actually applied mathematics in his life without realizing it. This can provide a reference for educators at home like parents, to provide mathematics learning at an early age.

There are a number of papers on educational innovation, identifying obstacles to innovation, and hinting at potential outlines for effective innovation (Peter, 20017). The practice of contemporary learning is inspired by four wellknown cognitive psychologists including Piaget, Vygotsky, Bruner, and Dienes (Novikasari \& Ifa$\mathrm{da}, 2016)$. Their idea is based on the theory of constructivism. The theory views children can be creative with knowledge that comes from mental activity to produce experience. Piaget (18961980) was famous on his idea of four stages of cognitive development in a child. In the second stage, the preoperational thinking stage (2-7 years), children at this stage can learn language quickly and capability to use symbols that represent real objects. Dienes Theory is a type of theory in learning mathematics from mathematician named Zoltan P. Dienes. The theory conveyed by Dienes, the form of presenting mathematics is real and pleasant to children. The application of this theory is to make learning designs in certain principles and stages. Abstract mathematical concepts are built from structures. It looks interesting for learning mathematics when it use Dienes theory. In that theory, learning can be presented attractively through manipulative objects, games, stories and dances. Dienes learning method is presented with an approach as children playing so that it can help them to find and understand the mathematical structure in that play happily and fun. This research use the basic concept of Deenes which presents interesting mathematics learning. Here are the results of children's lear- ning at the beginning of education with math story book reading as a sample of building locks curriculum and Montessori as a sample of pre- $\mathrm{K}$ mathematics curriculum.

The Montessori approach had a major influence on approaches to early childhood education. Many Montessori learning practices are used in early childhood education programs. The Montessori method has many choices that make early childhood education programs of higher quality and this also applies to its continuing popularity. This Montessori focuses on the philosophy of maturationism, which is a theory that explains that a child's conceptual knowledge depends on the level of his biological development. The main objective of Montessori education is to prepare children for navigate life by emphasizing the child's normal and maximum developmental process. Montessori education is based on the natural conditions of brain absorption and the spontaneous development of sensitive periods of children to support physical and psychological development, as well as direct children to be healthy and free.

Basically learning a child is different from adults (Maria, 1912), all it the absorbent mind so that it is easy to absorb. This unique ability occurs from birth to age 6 years. She observed that the child absorbs experiences from the surrounding environment through all of their senses then processes them through the brain. One of the phases mentioned by Maria Montessori from birth until around the age of 3 years, the child is in an absorbent mind unconscious. Since that time the child explores the environment through the senses, movements and absorbs the language of surrounding culture. At this time the child absorbs the experience but is not aware of it. For example, when children learn languages but their parents never taught it. Language is acquired by children without conscious effort.

For the use of the Montessori system at home, there are two conditions of sufficiency. The first thing, parents should not expect that the material in educating children is enough to produce miracles of educational results. Montessori learners do not "teach" ordinary, but optimize skills and effort. Learners must see, help, inspire, suggest, guide, explain, improve, inhibit their students. In addition, to contribute the development of new pedagogical knowledge and to develop learning method not only optimize investigation and experimental, but also strive for practical and constructive. The second thing is the child's development must be observed, education and teaching must be adjusted to the child's 
development. The basic principles of the Montessori method are: 1) Individual approach to learning; 2) A combination of academic and social education; 3) Cultivate children's curiosity, and encouragement to dare for explore; 4) Abstract concepts are clearly presented, 5) The skills and routines taught will be applied in their daily lives until adulthood

Math storybook reading can be called a story telling method. The method of telling a story is to tell or tell a story orally to students so that the story can be conveyed good messages. The method of storytelling is a method used by teachers to convey messages or subject matter on process of teaching and learning. For the story is adapted to the conditions of students. The storytelling method is one of the methods widely used in kindergartens. The storytelling method is one of the learning strategies that can provide learning experiences for early childhood. By telling stories to children orally, the story must be interesting so that it attrack attention of children. Furthermore, it can not be separated from the purpose of education for early childhood. The method of storytelling can be an alternative in introducing the mathematical concept of early childhood consisting of: numbers and operations, algebra, geometry, measurement (Jane, 2007).

The application of storytelling as one of the learning strategies in kindergarten must be noticed as follows: 1 . The content of the story must be related to the surroundings of early childhood education; 2 . Storytelling activities are optimized to provide feelings of joy, humor and fun according to the fascinate world of children's lives; 3 . Storytelling activities should be optimize the unique and interesting experience for pra-kindergarten children.

In this paper, some kinds of storytelling techniques are to read directly from books, to use illustrations from picture books, to use flannel boards, to use puppets, to play roles in a story, or to tell stories using fingers, and to tell stories using puppets. Since childhood, children try to build mental images of shapes, including geometric shapes. It is known that early children show the ability to slide, turn and reverse mental shapes in certain settings, and they can also produce and check mental images (Uscianowski, 2018). As in puzzles or story books, there are many forms that can be absorbed by children such as geometric puzzles and fairy tales that relate to arithmetic shapes and algebra. This research aims to provide solutions and ideas for parents in teaching children of early age (0-3) years old on mathematics.

\section{METHOD}

The research method used is based on literature studies. The primary objective of the present study was to develop and implement a conceptually broad early education mathematics as part of home intervention, and then to assess whether the intervention had positive consequences for children's mathematical development. The data reported in this study were collected with a sample of children who were designed to examine the developmental course and predictors of various mathematical abilities. The study was conducted through learning activities according to the age and the cognitive development of children (NCEERA, 2013). The mathematics learning use some home education learning innovations such are Montessori and math storybook reading with the help of books. It depend on cognitive development children so it related to journals and articles about mathematics in early education.

\section{RESULT AND DISCUSION}

Observers of educational innovations such as educators, learners, educational researchers and parents have a great influence on education. Its includes improving behavior, motivation, self-confidence, and comfortable learning for the quality of education. One of the way to improve the quality of education is to develop the quality of learning. Parents have an influence on early education, especially on learning at home. To deal with more complex mathematics learning in the future, it is necessary to prepare for the introduction of mathematics in the early days of education at home. Children who are not ready to learn in the conventional sense which is just sitting there for listening need some innovation learning so that they are capable to absorb material appropriate to their age and ability. Learning innovation is one of the educational innovations. Learning at home can be done as the solution, because learners are related to the ability of the brain by learning, identifying, and developing abilities repeatedly. Back to the nature of the child who likes to play and to increase parent-child bonding, so that the role of parents in learning at home is very important. Learning innovation is carried out as attractive as possible and according to the child's development at the beginning of his education. The learning innovations discussed in this paper are early education learning using Montessori and math storybook reading.

Knowledge about mathematics actually can be introduced to children from an early age 
(age of birth - 6 years). In children under the age of three, mathematical concepts are discovered every day through their play experiences. From this idea gave rise to mathematical learning innovation through play experience, by involving parents as educators without reducing children's play time. Children can also learn with parents so that it increase the chemistry of parent-child. According to the definition of early childhood mathematics education that has been described before, the authoruse it as a reference to make lesson plans in learning mathematics at the beginning of education. The learning start from the age of 0-3 years, because early childhood education has a school education starting at the age of 3 years. The results of the learning activities grouped by age, as follows age of 0 , age of 1 , age of 2 , and age of 3 .

\section{Age of 0}

Children always interest in different plays. They start playing before beginning to walk or speak. They look the plays as a work and they are in attention while they are playing. Interest and motivation is important for learning so play can be use as a fuctional tool for learning. On the other hand children live with mathematics in their daily life and they grow up with mathematics. The children learn mathematics from surroundings object. It said that from birth, all children start to observe mathematic. This is explained as: Introduction of geometric shapes and large-small measurements; The activity is hanging toys on the playmat while mentioning the name and size of small-large; Introduction of spherical geometry shapes and large-small measurements; Its activities include holding large and small balls while introducing and mentioning the names "big balls" and "small balls"; Introduction of geometric shapes such as squares, triangles, circles, stars. Its activity includeholding a stroller toy or teether in form of a triangle, rectangle, pentagon, star, circle.

\section{Age of 1}

In play activities infants under (1-2 years old) use their hands to understand math concepts and skills. It can be a play activity for them. This is explained as: Introduction of geometric shapes, size of large-small and measurement of shortlength; The activity is in the form of reading math stories that contain interesting color images and contain shapes and size of large-small, measurement long-short, arranging legos to imagined shapes; Introduction to the concept of sets by grouping
Activities by cleaning the toys according to their starting place, placing color ball to the same place for same color in glass, paper, or plates. It can be done by sitting or walking or running. Also, grouping of small paper in same shaped paper like triangular, circular, rectangular, square on big paper with same shape. It can also moving pompom into the glass according to same color or same size (large and small) with a hand or spoon; Introduction to geometric shapes; Activities by arranging geometry puzzles; Concentration training and introduction of high-low, long-short measurements; The activity consists of arranging upwards blocks and wooden cubes into towers

\section{Age of 2}

In this age, children can cope with great difficulties in their mathematics learning. Parents also can cope with great difficulties in their facilitation of children's learning. These difficulties can be solved if parents build relationships with the children in home. They can understand the command, it is how they play and learn so they can use it to solve realistic problems. Parents can develop challenging and complex experiences. They can help children to reach their potential in mathematics learning. This is explained as: Introduction of numerical symbols and arithmetic; The activities include playing number puzzles, grouping or equalizing magnetic numbers with number flashcards, reading math stories with interesting books about number recognition; Introduction of number symbols; The activity such as treasure hunt numbers by hiding magnetic figures in aluminum foil or in peces of papers and then mentioning the numbers. It can also using shadows that are formed from numbers highlighted by a flashlight in a dark room; Introduction of number symbols and sets.

The activity include grouping numbers into places that have been labeled by number symbol. It can also usingcolored sticks with numeric labels place so that amount of stick according to the numbers. It also learn the concept of counting.; Introduction to geometry. The activity is using geometry board games andruber which can forming triangles, squares, rectangles, trapezoid. It can also drawing basic geometry such as lines and points. Drawing activities can be done with on plain paper, whiteboards, or walls with a pencil, marker, or chalk so children don't get bored

\section{Age of 3}

From ages 3 through 6 , children need many experiences that call on them to relate their knowledge to the vocabulary and conceptual frame- 
works of mathematics. In other words, it called to "mathematize" what they intuitively grasp. Toward this end, effective early childhood programs provide many such opportunities for children to represent, reinvent, reorganize, quantify, abstract, generalize, and refine that which they grasp at an experiential or intuitive level. So in this age, the mathematics learning activities described as: Introduction to the concept of arithmetic

The activity use a circle cardboard which is drawn with a certain amount then cildren should clamp it with number symbol on clothes pins or paper clips . It can also readingmath stories about counting such as counting animals in a fairy tale, making number stickers so that children can paste it after counting. Geometry formation; The activity use sticking stick with tape or glue so that form the order to the exemplary shape such as square, triangle, trapezoidal, rectangular, pentagonal; Introduction of arithmetic; The activity includesorting numbers using flashcards, magnetic numbers, or number stickers; Introduction to the concept of addition; The activity useright-left hand drawings so that children can calculate by adding unfolded right and left hands. it can use color pompoms such as counting yellow with red. Also it can use geometric blocks such as counting prism-shaped blocks with a cube-shaped.

Mathematics education in early childhood is very important to developed. Mathematics learning education must be trained everyday and interested as possible. Home learning innovation is highly recommended because early childhood mathematics education depends on motor skills repeatedly and still on play stage, so learning must be done with playing and increasing motor skills stimulus. Mathematics education in early childhood is expected to prepare children for daily life and to prepare more complex forward mathematics education. Mathematics is very important to be taught since early childhood, because mathematics integrates with everyday life such as recognizing large-small measurements, recognizing the shape of objects around. After getting mathematics learning at the beginning of education, children feel confident following mathematics learning at school because the introduction of mathematics has been obtained. Children also easy to take learning mathematics in school without any difficulties. There is forwardness in learning basic things such as the introduction of numerical symbols, basic geometric shapes, and sets.

Explicit mathematics instruction in preschool typically consists of an assortment of mathematics topics, often without careful thought about what young children are mathematically capable of and what might be important for their subsequent success in kindergarten and beyond (Star \& Ritlle, 2016). One team (Starkey and Klein) are both psychologists, while the other team (Clements and Sarama) are both mathematics educators (who attend carefully to learners' mental processes, with publications in psychology journals). While efforts to develop and evaluate preschool mathematics curricula predates their work, these research efforts have significantly thinking about the types/level of mathematics that children can and should learn in preschool and carefully attends to children's mental processes. In the psychological test, there is no test result that leads to emotion and pressure effect.

\section{CONCLUSION}

The participation of parents in learning mathematics at home is being able not only to increase the bonding of children-parent but also to prepare mathematics learning outside from home such as at school. This activities had two advantages, playing and learning concept basic of mathematics. Mothers who always accompany their children at home can also do learning activities without fear of running out of ideas playing together or fear of boredom playing. Learning innovation can be done using the Montessori method and reading math stories. Learning innovations can be a solution to the idea of playing with children, when parents are busy working then they can spend time for playing and learning with children especially mathematics. As long as learning mathematics is done as interestingly and fun as possible then it done with parents by playing together, learning mathematics at the beginning of education does not have a negative impact. Learning activities at home also conditioned according to the child's condition such as not in a forced, sleepy, or hungry condition. Such things can only be done by their closest which is suitable to the parents. This learning should be repeated according to a schedule so that children will understand and catch the concept. So there is a link between the participation of parents at the beginning of education and the development of children's education, especially in the field of mathematics. In other words, the role of parents in the innovation of mathematics learning in early education is very influential on forward of children's mathematical abilities.

The things need attention is dedicate time each day to teaching math, and integrate math instruction such as plan daily instruction targe- 
ting specific math concepts and skills, embed math in home routines and activities, also highlight math within topics of study across the curriculum. It need to create a math-rich environment where children can recognize and meaningfully apply math. And active learning to teach math concepts and skills and to give children practice in applying them. The learning must have lesson plan, so before doing the learning it must be checked if it suitable for the age (0-3) years and the capabilities. The lesson plan include theme, concept, activities, and goal of learning as a curriculum mathematics in early education. Furthermore, the activities can be repeated once a week as it schedule or daily plan. Time for learning is fleksible, it depend on play time of the child. Observations were made covering all activities of parents and children in mathematics early education learning. For make sure that it had positive consequences for children's mathematical development, the child get psikological test after mathematics learning trough $0-3$ years.

\section{REFERENCES}

Ardita, C., \& Rabije, M. (2016). The Role of Parents in the Education of Children. Journal of Education and Practice, 7(5), 61-64.

Cyrus, R. (2010). Early Childhood Education. Journal of College Teaching \& Learning, 7(1), 1-8.

Dina, K. W. (2017). Peran Guru dalam Menerapkan Pembelajaran Matematika yang Menyenangkan bagi Anak Usia Dini. Jurnal PAUD Agapedia, 1(2), 153-159.

Dooley, T., \& Dumphy, E. (2014). Mathematics in Early Childhood and Primary Education (3-8 years). Dublin Irlandia: National Council for Curriculum and Assessment.

Institute of Education Science. (2013). Pre-K Mathematics with DLM Early Childhood Express Math. WWC Intervention Report.

Jane B., \& Jane M. (2007). The impact of storybooks on kindergarten children's mathematical achievement and approaches to learning. USChina Education Review, 6(7), 61-67.

Khadijah, (2016). Pengembangan Kognitif Anak Usia Dini. Medan: Perdana Publishing.

Maria, M. (1912). The Montessori Method Scientific Pedagogy as Applied to Child Education in The Children's Houses with Additions And Revisions. New York: Frederick A. Stokes Company.

National Association for the Education of Young
Children and the National Council of Teachers of Mathematics. (2002). Early Childhood Mathematics: Promoting Good Beginnings. Position Statement.

National Center for Education Evaluation and Regional Assistance. (2013). Teaching Math to Young Children. Institute of Education Sciences: U.S. Department of Education.

Novikasari, I. (2016). Matematika dalam Program Pendidikan Anak Usia Dini. Bunayya: Jurnal Pendidikan Anak, 2(1), 1-16.

Peter, S. (2017). Innovation in education: what works, what doesn't, and what to do about it?. Journal of Research in Innovative Teaching \& Learning, 10(1), 4-33.

Perry \& Dockett. (2007). Early Childhood Mathematics Education Research:What is Needed Now?. Mathematics: Essential Research, Essential Practice. Volume 2. Proceedings of the 30th Annual Conference of the Mathematics Education Research Group of Australasia

Rose, K., Vukovic, S. O. R. \& Wright, L. G. (2013). From Parental Involvement to Children's Mathematical Performance: The Role of Mathematics Anxiety. Early Education \& Development, 24(4), 446-467

Sarama, J., \& Clement, D. H. (2002). Building Blocks assessment of early mathematics pre- $K$. In Press: Columbus, OH:SRA/McGraw-Hill.

Sarama. J., \& Clement, D. H. (2007). Effect of Preschool Mathematics Curriculum: Summative Researcher on The Building blocks Project. Journal for Research in Mathematics Education, 38,(2), 36-163.

Star, J. \& Rittle-Johnson, B. (2016). Toward an educational psychology of mathematics education. In L. Corno \& E. Anderman (Eds.) Handbook of Educational Psychology. Third edition. (pp. 257-268). American Psychological Association. New York, NY: Routledge.

Starkey, P., \& Klein, A. (2000). Fostering parental support for children's mathematical development: An intervention with Head Start families. Early Education and Development, 11(5), 659-680.

Starkey, P., Klein, A., \& Wakeley, A. (2004). Enhancing young children's mathematical knowledge through a pre-kindergarten mathematics intervention. Early Childhood Research Quarterly, 19(1), 99-120.

Uscianowski. (2018). How Parents Support Early Numeracy Development During Shared Math Storybook Reading. The Executive Committee of the Graduate School of Arts and Sciences, New York City, Columbia University. Doctor of Philosophy. 